\title{
Intersection of Open Data and Freedom of Information Practice in Nigeria
}

\section{Omenogo Veronica Mejabi*, Adesina Lukuman Azeez*, Adeyinka Adedoyin*, Muhtahir Oluseyi Oloyede*}

*University of llorin, Nigeria - \{ovmejabi@gmail.com, azeez.al@unilorin.edu.ng, adedoyin.a@unilorin.edu.ng, oloyede.om@unilorin.edu.ng\}

Abstract: The Freedom of Information (FOI) Act was enacted in Nigeria in 2011. However, Nigeria has been publishing its national budget online since 2007. This paper presents results from a survey in which several stakeholder groups connected to the online national budget of Nigeria were asked to respond to questions of awareness and use of open data and the Freedom of Information (FOI) Act. The results show that respondents who were aware of Nigeria's 2011 FOl Act made the link with open data practice but indicated that citizens were not taking enough advantage of the Act. Also, custodians of data or information were likely to seek ways to avoid meeting such requests. Nevertheless, Nigerians need to be more educated on the key elements of the Act for its proper and adequate utilization or invocation, which could affect more positively on open data initiatives in Nigeria.

Keywords: Freedom of information, right to information, open data, open budget data, Nigeria

\section{Introduction}

Many changes within the public sector have occurred the last two decades, from new public management in the mid $80^{\prime}$ s, to the arrival of computers, software programs and digital management since the mid 90's. In addition to these transformations, transparency has become a keyword in the process. To foster this, Freedom of Information (FOI) regulations have spread the world over in the past 25 years ensuring that citizens have the right to request information from government and making governments publish and provide information to its citizens. Albu and Flyverbom (2013) observed "that transparency is more often invoked than defined, more often preached than practiced". They further pointed out that transparency acts as a solution to governance, economic growth, control of corruption, and citizen participation.

Open government data is the latest chapter of the governance story; it has become a prominent topic for policymakers, academics, computer scientists, civil society organizations, technology corporations, and geeks. In 2007, Sir Tim Bernes Lee, founder of the World Wide Web, led in inviting people to claim their right to government-held data as a vehicle to achieve greater 
transparency and accountability, better public services, and leverage a more equitable economic growth (Joshi, 2010). The introduction of open data has energized political power and information and rights issues in developed countries. Improvement of services and contribution to economic growth has been made possible by making information about services and education data amongst other information publicly available on the web (IIEA, 2011). Reasons given for implementing open data portals are that it acts as a platform for improved transparency, catalyses innovation, and enables social and economic development.

In line with the Open Government Directive spearheaded by the United States government in 2009, a move towards open data as a formalized policy direction of the Government of Nigeria began in January 2014. However, various data sets providing information on developmental and governance issues have been available for years on various websites of public and private sector organizations. One of such is the publication of the budget of the Federal Government of Nigeria through the website of the Budget Office of the Federation on http://www.budgetoffice.gov.ng, since 2007. One of the 36 states of the Federation, Edo State, became the leading technology-driven state in Nigeria with the launch of its open data on the 13th of September 2013 (Author, 2014).

The emerging open government data activities in Nigeria are being encouraged by the Freedom of Information Law that was signed in the country on the 28th of May 2011. The law acts to make public records and information more freely available, provide for public access to public records and information, protect public records and information to the extent consistent with the public interest, and the protection of personal privacy. It also protects serving public officers from adverse consequences for disclosing certain kinds of official information without authorization and establishes procedures for the achievement of those purposes and related purposes thereof (FOIA, 2011). Thus, the Freedom of Information law has based its mission to promote open and democratic government in Nigeria through advocacy for public access to information, participation in governance and vocal participation with diverse constituencies, grassroots, civil society groups, and government institutions (FOIA, 2011).

Within the framework of the key elements of the Nigeria Freedom of Information Act, this paper explores the interrelationship between open data and FOI from the perspective of Nigerian citizens as part of a wider study on citizen engagement with the online national budget data in Nigeria. It sought to answer the following specific questions:

1) What is the extent of awareness of open data and the Freedom of Information Act (FOIA) among the major stakeholders in the Nigerian open budget data ecosystem?

2) To what extent have the stakeholders been invoking or using the FOIA to request public information?

3) To what extent have government MDAs supplied information in response to requests citing the FOIA?

4) To what extent has the FOIA been promoting access to public information and records, such as the national budget of Nigeria?

5) What is the opinion of stakeholders on how the FOIA could impact on the drive for open data in Nigeria? 
The paper answers these questions by examining the response to questions about the awareness of open data and freedom of information legislation in Nigeria and makes an assessment and evaluation of the extent and ways in which these freedoms and provisions are being used. The context of the methodology and discussion that follows is set in the following section which outlines the FOIA in Nigeria and selected studies on implementation of FOIA in other countries.

\section{Literature Review}

Literature, generally, has associated reasons and benefits for the enactment of Freedom of Information Acts overly to the true essence of democracy. It is assumed that the Act promotes a democratic system of government by allowing everyone to express their opinion and access information (Banisar, 2006; Offiong, 2013).

Because the Act proposes that everyone, including media practitioners, is free to access, receive, and impart information without intimidation, the Freedom of Information Act functions as a vital instrument through which media practitioners, as well as other stakeholders, in the open data ecosystem uphold democracy and function properly as the fourth estate of the realm. It helps the citizens hold government accountable for their actions and inactions, ensures transparency and limits corrupt practices in governance (Banisar, 2006; Offiong, 2013, Adeleke, 2011; Afolayan, 2011).

Article 19 of the Global Campaign for Free Expression, an international human rights nongovernmental organization, describes information as the driving force of democracy. Specifically, it argues that information is the "Oxygen of Democracy". Likewise, Thomas Jefferson affirmed that "information is the currency of democracy". Impliedly, information is critical to the smooth performance of democracy. Hence, democracy cannot exist without freedom of expression and freedom of the press.

Consequently, according to Offiong (2013), the FOI Act was enacted in Nigeria to enhance media professionalism so that journalists will be free to "dig" and "pry" in order to collect information freely and publish without hindrance; and every Nigerian should be free to access, have an opinion and impart information, while journalists also must be free to carry out their social responsibility functions as the fourth estate of the realm without hindrance. Significantly, Ogbondah (2003) noted that the Freedom of Information Act was enacted due to the failure of Nigeria's 1999 constitution to guarantee people generally and the press particularly freedom of expression and freedom of the press, both of which are essentials in every democratic practice.

Mendel (2008) suggests that effective participation of citizens is achieved when people access information from public institutions, provide useful information on public policy and government plans of actions and day-to-day government activities, make informed decisions of who will represent, and participate in elections through voting. For instance; access to information about office seeking political candidates will help the electorate to make an informed and right decision on whom they want to represent them in government. 
Costa (2009) reiterated that free press is fundamental to proper monitoring and investigation of government officials and power abuse in a country. It helps in the easy collection and access to information and checks of the governments. However, this may only be true in situations when the press is non-partisan and completely outside the ruling government.

Since the global popularity and recognition of the importance of Freedom of Information laws, the level of adoption has increased dramatically. Countries like the United States of America adopted the FOIA in 1966, Sweden (1766), Angola (2002), Argentina (2003), Australia (1982), Bosnia (2001), Bulgaria (2000), Canada (1983), Colombia (1985), Denmark (1985), Germany (2005), India (2005), South Korea (1996) (Banisar, 2006) and Nigeria (2011), among others. These countries have all embraced FOIA as a fundamental human right of the citizenry. The Freedom of Information Act is an indispensable Act of democracy and an essential tool of effective media practice and seems to be complementary to calls for open data. Hence, this study aims to explore the intersection between open data practice and the Freedom of Information Act to provide evidence for or against this assumption.

\subsection{Emergence of the Freedom of Information Act in Nigeria}

The idea of a Freedom of Information law for Nigeria was first conceived in 1993 by three different independent organisations: The Media Rights Agenda (MRA), Civil Liberties Organisation (CLO), and the Nigeria Union of Journalists (NUJ) (Coker, 2011). Efforts of these initial partner organisations were geared, among other things, towards determining the various interest groups likely to be affected by the legislation and under what circumstances information may be denied to those seeking the information, what organs or departments of government should be responsible for releasing information and documents to those seeking them. The Media Rights Agenda was designated as the technical partner and was given the responsibility of producing a draft copy of the Freedom of Information Law, which it produced in 1994 (FOIC, 2011). So, it took seventeen years for the act to emerge from the first draft.

The draft bill, which was initially entitled "Draft Access to Public Records and Official Information", drew substantially from the experiences and contents of countries already operating Freedom of Information Law, particularly the United States of America. The gag on freedom of speech by the various military dictatorships in Nigeria also motivated the pursuit of an FOI law. The draft document formed the basis for further discussions and debates on the issue and was subsequently subjected to a series of review exercises involving many other stakeholders such as human right workers, civil societies, journalists, lawyers, university lecturers, and representatives of the National Broadcasting Commission as well as the Federal Ministry of Information. At the workshop, efforts were made to revise the draft produced by MRA, with the aim of arriving at a consensus that was agreed upon by all the various interest groups, and that would be affected by the availability of a legally protected right of access to government-held information. A revised second draft of the proposed legislation was later updated that year to reflect the consensus of the participants at the workshop.

A campaign for the enactment of the bill began in 1995, and it was intensified until the civil regime of Chief Olusegun Obasanjo emerged in 1999. To further the campaign, another workshop 
to review the draft law was organized between March 16 and 18, 1999 in Ota, Ogun state, and it was attended by stakeholders that included representatives of the media, legal profession, international institutions, local and international non-governmental organisations, and many other interest groups. After it was presented to the Federal House of Assembly with powerful lobbies, the bill was passed and signed into law in 2011 by the Goodluck Jonathan administration.

Subject to the provisions of the Act but notwithstanding anything contained in any other act, law or regulation, the FOIA grants every citizen of the Federal Republic of Nigeria a legally enforceable right to, and shall, on application be given access to any record under the control of a government or public institution (Section 2, FOIA). However, "the applicant need not demonstrate specific interest in the information being applied for" (Section 2 (2)). The law also stipulates that any person entitled to the right of access conferred by the Act shall have the right to institute proceedings in a Court to compel the head of any government institution or public body to comply with the provisions stipulated in Section 3 (3) of the Act.

To seek access to any information or record from any government department or agency, an application for access must be made in writing to the government or any public institution that has control of the record and shall provide sufficient detail to enable an experienced employee of the institution with a reasonable effort to identify the record (Section 4). The Act specifically states that where access to records is applied under the Act, the head of the government or public institution to which, the application is made shall, subject to Section 7, 8 and 10 of the Act not later than fourteen working days following the date of receipt of the application (Section 5), give written notice to the person who made the application as to whether or not access to the record or a part thereof will be given (Section 5a); and if access is to be given, give the person who made the application access to the record or part thereof (Section 5b. In counting the fourteen working days, the date on which the fee is received by the head of the government or public institution is not counted (Section 5 (2)). In case the application for access is refused, the Act enjoins the head of government or institution to state in the notice the specific provision of the Act on which the refusal was based and shall indicate in the notice that the person who made the application has a right to have the decision reviewed by a Court (Section 8).

Essentially, the head of government or public institution may refuse to disclose any record, if the disclosure may be injurious to the conduct of international affairs or the defence of the Federal Republic of Nigeria, injurious to a person or that can interfere with pending or actual and reasonably contemplated law enforcement proceedings conducted by any law enforcement or correctional agency, or that can deprive a person of a fair trial or that can disclose the identity of a confidential source or that constitute an invasion of personal privacy although where the interest of the public would be better served by having such record being made available, this examination to disclose shall not apply (Section 13 and 14). Other exceptions that can make any head to refuse a disclosure include anything that has to do with the economic interest of the Federal Republic of Nigeria, third party information, legal practitioner-client privilege, course/research materials, test questions, scoring keys, other examination data, architects' and engineers' plan for building not constructed with public funds and library circulation (Section13, 14, 15, 16, 17, 18, 19,). However, court order to disclose or release any record as well as outweighing public interest overrides all 
these exceptions. Indeed, the Act stipulates that even the record kept in the custody of government or public institution under security classification or is classified document within the meaning of the Official Secrets Act is not precluded from being disclosed if an application for its disclosure is made (Section 30). The head of government to which such application is made has the discretion to decide if the record or information being sought for falls under the categories of exceptions in Sections 14, 15, 16 17, 18, 19, 20 or 21 of the Act.

Mendel (2008) pointed out that the Act promotes the culture of openness among public officers. Abia (2012) also notes that the Act fosters an effective strategy towards ensuring development, tackling poverty, and avoiding non-representative public policies. The Freedom of Information Act is expected to benefit all sectors of the economy, government, and the society at large by promoting an open system of governance, open data culture, and an open society.

\subsection{Empirical Studies on the Implementation of Freedom of Information Act}

Scholars and media practitioners generally have agreed that FOIA is the most useful weapon of democracy and a tool in tackling corruption (Neuman, 2005; Mendel, 2005 \& 2008; Agande, 2011; Afolayan, 2011; Freedominfo.org, 2016). In this regard, researchers over the years have measured the effectiveness of the Act in enhancing democracy and openness in different societies.

Along these lines, Banisar (2006) declared that the FOIA helps to protect citizens' rights, as well as supports fairness, equality, and participation of the citizenry in government. By using a survey method to examine the adoption of the Act in these countries, he investigated the level of awareness and adoption of the FOIA, as well as how the Act works in over 70 countries around the world. He found that adoption of the FOI law enhances fundamental human rights, openness in government, equality, effective participation in governance and protection of citizens' rights.

Some of the experiences reported by Banisar (2006) include the situation in India where the FOIA was used to make government responsive to the long-standing needs and aspirations of the citizens such as; provision of roads, job opportunities, availability and equal distribution of food and other basic needs and social amenities among the masses. In Thailand, the FOIA aided the establishment of equality and fairness. Meanwhile, FOIA has been used in Brazil to establish transparency and accountability in governance as government and its public institutions proactively publish information publicly online on budgetary and other operations that concern the people. Also, media practitioners in the country have drawn on the law, using it to monitor government activities, identify inconsistencies, and reveal corrupt public officials. The FOIA in Brazil has also encouraged a lot of investigative journalism practices in the country leading to the public prosecution of corrupt officials and resignation of some ministers in the country (Martini, 2014).

From another perspective, Hayes (2009) examined how Mexicans explored FOIA since it became law in 2005 and found an increase and significant use of the law due to "pent-up demand" during the five years of waiting for the bill to come into legal effect. Hayes found that there were superfluous inquires for information not only from public agencies across the country but to broadcast organizations, armed forces, and the health sector. Though the number of requests fell as 
time went on (e.g., falling from 13,500 in 2005 to 8,000 by 2008), it was discovered that Mexicans, mainly journalists, explored the freedom of information law so much that government officers complained of enormous work in responding to the requests and Mexican journalists were attacked for overuse of the Information Act.

Banisar (2006) suggested that many countries adopt FOIA due to some internally influenced factors, and, importantly, the significant roles of civil society groups such as the media, anticorruption groups, and environmental groups. The internal factors include corruption and scandal, international pressure and modernization and the information society. Costa (2009) examined how the adoption of FOIA in a country affects peoples' perception of corruption and the quality of governance using various perceptions of corruption both at the micro and macro levels. Based on results from the research carried out in transition countries by The World Bank and the European Bank for Reconstruction and Development in 1999, 2002, and 2005, and corruption indices from the International Country Risk Guide and Transparency International, Costa adopted different methods to examine whether peoples' perception about corruption in governance changes after the adoption of FOIA in a country. The research showed that adoption of FOIA is not sufficient enough in achieving accountability in government and reduction in corrupt practices in a country because the use of the law does not change peoples' perception of corruption.

To support this finding, Cordis and Warren (2012), Omotayo (2015) and Dawodu (2016) reiterated that countries must implement strong freedom of information laws, together with effective press freedom, to contain corrupt practices among government officials. Thus, Cordis and Warren (2012) postulated that strengthening freedom of information laws in a country produces two likely effects: it reduces the level of corruption and increases the probability that corrupt practices are easily detected. Findings from the study showed that the use of strong freedom of information laws leads to an increased rate of corruption convictions. The findings also suggest an increase in detection of corrupt practices in the state.

Accordingly, Haynes (2009) concluded that for FOIA to have positive effect and achieve sustainable changes in the society, its adoption must be enforced by the following;

i) Freedom of the press and association

ii) Effective mechanism for checks and balancing of government actions and inactions

iii) Established structure for prosecution and dismissal of any public officers guilty of corruption; and

iv) Creation of policy that addresses problems affecting quality service delivery.

The second point above buttresses one of the flaws of the Nigeria FOIA whereby it ascribes so much power to government officials to regulate the outflow of information upon request while also protecting them from public criticism or prosecution, if guilty of any gross misconduct, a point made by Agande (2011) while submitting that Nigeria's FOIA failed to address the main purpose of its enactment. 


\subsection{Factors Affecting the Implementation of Freedom of Information Act in Nigeria}

It is important to state here that studies on the use and challenges to the use of the Freedom of Information law in Nigeria are few (Omotayo, 2015). The few studies related to the subject matter only examined the opinions of respondents on the potential benefits of the law on journalism practice and the country at large. One of the studies by Abia (2012) evaluated the significance of Freedom of Information Act in enhancing journalism practice and democracy in the country surveying the opinions of 328 journalists (both in government and private organizations) in River state. The result showed that many of the journalists had an understanding of the relevance of the FOI laws and followed its cause keenly towards its effectiveness in the state. Similarly, they all agreed that the Act helps journalism practices and also has the potential to aid in transparency and participatory governance in the country.

In the same vein, Offiong (2013) surveyed the impact of Freedom of Information Act on journalism practice among 80 journalists in Uyo community and found that many of the participants opined that the law affects journalism practice positively such that it enables free access to information and expression of opinion about government without hindrance. The result also indicated that the Act encouraged investigative journalism among practitioners in the community on salient issues of national significance.

From the above, it is obvious that the studies by Abia (2012) and Offiong (2013) are limited in scope because both are focused only on the opinions of journalists. These results reveal that there is a scarcity of empirical research on the implementation of FOIA among journalists and other members of the public in Nigeria, which then called for this study. On this, Omotayo (2015) opined that the scarcity of empirical works on the use of freedom of information laws in Nigeria indicates there is low implementation of the law in Nigeria. He further noted that the people (journalists and everyone) to whom the law gives access and for whom the law was enacted are not proactive in the usage of the law.

Hayes noted that for the FOI law to be effective in a country; journalists and members of the society must meet the following requirements;

a) Have the capacity to prepare a well-phrased request for information

b) Have an understanding of the information that is likely to be released

c) Have a knowledge of what information is held and by whom

d) Have an understanding of what or which information will be useful (Hayes, 2009).

These requirements suggest that a country that wants to enjoy the potentials of FOI laws must orientate the public and journalists on how to use the laws appropriately.

Research has shown that the Freedom of Information Act in Nigeria suffers poor implementation and appropriate use among journalists and members of the public generally since the bill was signed into law. The reason for this, according to Afolayan (2011) and Omotayo (2015) are some internal factors militating against the use of the Act in Nigeria. Ogbuokiri (2001) maintains that the excessive exemptions and clauses contained in the law stand as a significant challenge towards the effectiveness and proper implementation of freedom of information law in 
Nigeria. Similarly, Omotayo (2015) emphasized that the poor usage of freedom of information laws in Nigeria is influenced by some internal factors such as:

- Strong culture of secrecy

- Poor understanding of members of the public on FOI law some of which is because the law is written in English language and government remains unconcerned about the barrier of language in the country.

- Low level of public awareness and implementation

- Poor record keeping mechanisms by ministries, departments, and agencies of government, so assurance that some information that might be requested for disclosure by members of the public will be available is not guaranteed.

Significantly, Adeleke (2011) and Omotayo (2015) state that conflicting laws such as the Official Secrets Act, the Criminal Code, the Penal code, Evidence Act, the Public Complaints Commission Act affect the implementation and effectiveness of the Freedom of Information Act in Nigeria. These laws also protect government officials from public criticism and corrupt practices which militate against the positive impact of the Act in serving the public interests. Therefore, until these challenges are addressed, the freedom of information law will remain insignificant in the Nigeria society.

By and large, the identified problems mitigating against the effective implementation of the FOIA in Nigeria, demanded for this particular study to further investigate the extent of awareness of the Act, the extent to which stakeholders have been utilising the Act, and the opinion of stakeholders on how the FOIA has been impacting on open data practice in Nigeria.

\section{Methodology}

Data for the study were collected between January and May 2014 from respondents expected to be familiar with Nigeria's budget data and the presence of the data online through the website of the Budget Office of the Federation. A purposive sample of 161 respondents was targeted out of which 94 consented to participate in the study, representing $58 \%$ of the targeted sample.

The research design adopted the concept of supply of, and demand for, data. On the supplyside, respondents targeted were government personnel from the Budget Office of the Federal Ministry of Finance where the budget is prepared and legislators from the National Assembly who approve the budget. The Office of the Accountant General of the Federation was also identified as a potential source of respondents. In all, 30 respondents were targeted on the budget data supplyside.

On the demand-side, the targeted respondents included three journalists each from selected newspaper houses and television stations (27 in all); three key persons each from ten CSOs/NGOs (30 in all). Three respondents from each of ten MDAs were chosen due to the following factors: their assumed relationship to data use (such as National Population Commission, Federal Character Commission), right to information (Federal Ministry of Information, Federal High Court, Abuja), and importance to the Federal Government's Vision 20:2020 plan, as well as from 
the Millennium Development Goals (MDGs) (such as the Federal Ministry of Education, National Universities Commission, Ministry of Health, Ministry of Agriculture, National Centre for Women Development). The Federal Ministry of Communication Technology was targeted because of its role as the chair of the planning committee for the National Open Government Data Initiative. This resulted in 30 targeted respondents for government personnel on the demand-side. Respondents grouped as others were the staff of eight professional/business associations, three each and independent experts such as visible budget, political, financial analysts and social critics identified from television, newspaper, and social media sites, and re-packagers of budget data (44 in all). Most of the shortfall in the number of respondents came from this cluster.

The survey and interviews took the researchers almost six months to conclude, because the respondents and participants in the study were sampled from Lagos, the hub of Nigeria media practitioners, Abuja, the seat of the Federal Government of Nigeria, and Benin, the capital of Edo State, which is the vanguard of open data initiatives in Nigeria. The target sample included a high number of top-level management personnel and obtaining access and consent to be part of the study was a significant challenge. The number of respondents achieved was because of the letters of introduction provided by the researchers' institution and the tenacity of the researchers in repeatedly following up on their allotted targets.

The resultant sample comprised the following clusters of stakeholder groups:

- $\quad$ civil society $(17 ; 18.1 \%)$

- government personnel involved in the preparation of the national budget including Legislators involved with the budget committee (termed "government supply-side" for this study) $(23 ; 24.5 \%)$

- government personnel from selected ministries and agencies (MDAs) (termed "government demand-side") (22; 23.4\%)

- media professionals $(25,26.6 \%)$, and

- "Others-demand" (which included respondents from professional associations, repackagers of budget data, independent personalities) $(7 ; 7.4 \%)$.

Data were collected using questionnaires administered in person by each of the researchers, and which included both closed and open-ended questions on awareness, practice, and suggestions. The questionnaires administered can be found in the appendices of Author (2014). In all clusters, several visits were required to achieve the response rate required. A form to confirm informed consent was obtained from each respondent before proceeding with the survey or interview.

A further in-depth interview was conducted with 15 key stakeholders purposively selected across all the five stakeholder groups. The primary purpose of the in-depth interview was to obtain deeper and richer information on the stakeholders' use of the FOIA and their opinion on how the FOIA impacts on the open data movement in Nigeria. On average, an interview lasted about 40 minutes. Interviews were summarised in the interview guides provided and in very few cases where the subject consented, recording of the interview was done.

The quantitative data collected was presented using cross tabulation tables to show the contrast across stakeholder groups. Responses from the in-depth interviews were analysed thematically 
with sufficient verbatim quotes, which were adequately contextualized, to answer the research questions.

\section{Results}

\subsection{Research Question 1: Awareness of Open Data and FOIA among the Stakeholders}

Respondents were asked if they were already aware of the phrase "open data" before seeing the study questionnaire. Their responses are presented in Table 1.

Table 1: Respondent Awareness of the Phrase "Open Data"

\begin{tabular}{lccclcc}
\hline \multirow{2}{*}{$\begin{array}{l}\text { Aware of the } \\
\text { phrase }\end{array}$} & \multicolumn{4}{c}{ Category } & TOTAL \\
\cline { 2 - 5 } “Open Data" & $\begin{array}{l}\text { Civil } \\
\text { Society }\end{array}$ & $\begin{array}{l}\text { Government } \\
\text { demand-side }\end{array}$ & Media & $\begin{array}{l}\text { Others } \\
\text { demand }\end{array}$ & $\begin{array}{l}\text { Government } \\
\text { Supply-side }\end{array}$ \\
\hline No & $6(35 \%)$ & $12(55 \%)$ & $9(36 \%)$ & $3(43 \%)$ & $4(18 \%)$ & $34(36 \%)$ \\
Yes & $11(65 \%)$ & $6(27 \%)$ & $13(52 \%)$ & $4(57 \%)$ & $18(78 \%)$ & $52(55 \%)$ \\
No response & $0(0 \%)$ & $4(18 \%)$ & $3(12 \%)$ & $0(0 \%)$ & $1(4 \%)$ & $8(9 \%)$ \\
TOTAL & $17(100 \%)$ & $22(100 \%)$ & $25(100 \%)$ & $7(100 \%)$ & $23(100 \%)$ & $94(100 \%)$ \\
\hline
\end{tabular}

$\mathrm{N}=94$

Most stakeholders understand the concept of "open data" (above 55\% in most cases), except for Government officers on the demand-side where only 33\% of them were aware of the phrase "open data" before our study. They are followed by other demand-side stakeholders (from professional associations and independent analysts) where $43 \%$ of the respondents were not aware of the phrase "open data". Most of the respondents on the supply-side were aware of the phrase "open data" and understood the concept before the survey was done. Few respondents (18\%) that were not previously aware and did not understand the concept or what it means came from among the lawmakers from the government supply-side.

Respondents were also asked if they were aware of the Freedom of Information Act which was signed into law in Nigeria in 2011 and their response is shown in Table 2. Examination of the results in Table 2 shows that while all the respondents involved in the production of the budget data (government supply-side) indicated awareness of the FOIA, 64\% of the respondents from other MDAs did not respond at all to this question. Indeed, during administration of the study questionnaire, the researchers observed that many of the respondents in this category were reluctant to offer an opinion about FOI.

Table 2: Awareness of the FOI Act

\begin{tabular}{lcccccc}
\hline \multirow{2}{*}{$\begin{array}{l}\text { Aware of the } \\
\text { FOI Act }\end{array}$} & \multicolumn{5}{c}{ Category } & TOTAL \\
\cline { 2 - 6 } & $\begin{array}{l}\text { Civil } \\
\text { Society }\end{array}$ & $\begin{array}{l}\text { Government } \\
\text { demand-side }\end{array}$ & Media & $\begin{array}{l}\text { Others- } \\
\text { demand }\end{array}$ & $\begin{array}{l}\text { Government } \\
\text { Supply-side }\end{array}$ \\
\hline No & - & $1(4 \%)$ & - & $1(14 \%)$ & - & $2(2 \%)$ \\
Yes & $14(82 \%)$ & $7(32 \%)$ & $18(72 \%)$ & $4(57 \%)$ & $23(100 \%)$ & $66(70 \%)$ \\
No response & $3(18 \%)$ & $14(64 \%)$ & $7(28 \%)$ & $2(29 \%)$ & - & $26(28 \%)$ \\
TOTAL & $17(100 \%)$ & $22(100 \%)$ & $25(100 \%)$ & $7(100 \%)$ & $23(100 \%)$ & $94(100 \%)$ \\
\hline
\end{tabular}


$\mathrm{N}=94$

A further analysis of the responses to awareness of open data and the FOI Act was done by cross-tabulating one against the other which shows that just over $50 \%$ of the respondents were aware of both open data and the FOI Act. Also, of those respondents who were not aware of open data, $14 \%$ of them were aware of the FOI Act, and this could be attributed to the publicity generated during the years of advocacy before the FOI bill was signed into law.

Table 3: Cross-Tabulation of Respondent's Awareness of Open Data and the FOI Act

\begin{tabular}{lcccc}
\hline \multirow{2}{*}{$\begin{array}{l}\text { Awareness of } \\
\text { the phrase }\end{array}$} & \multicolumn{3}{c}{ Awareness of the FOI Act } & TOTAL \\
\cline { 2 - 4 } "open data" & No & Yes & $\begin{array}{c}\text { No } \\
\text { response }\end{array}$ \\
\hline No & $1(1 \%)$ & $13(14 \%)$ & $20(21 \%)$ & $34(36 \%)$ \\
Yes & $1(1 \%)$ & $51(54 \%)$ & - & $52(55 \%)$ \\
No response & - & $2(2 \%)$ & $6(6 \%)$ & $8(9 \%)$ \\
\hline Total & $2(2 \%)$ & $66(70 \%)$ & $26(28 \%)$ & $94(100 \%)$ \\
\hline
\end{tabular}

$\mathrm{N}=94$

\subsection{Research Question 2: Extent to which relevant stakeholders have invoked the FOI Act to request information}

Of the 66 respondents that indicated awareness of the FOI Act (see Table 3), 36 of them are from outside government: that is, respondents from civil society (14), media (18) and "others-demand" (4). Of these, more than a third, 39 percent, have invoked the FOIA to obtain information. Their responses are summarised in Table 4. Surprisingly, a small proportion of the media have invoked the FOIA (17\%) compared to $64 \%$ from civil society. Clearly, this is an area for further examination as to why the media is not using or invoking the FOI Act as much as expected.

Table 4: Used the FOI Act to Obtain Information

\begin{tabular}{lcccc}
\hline \multirow{2}{*}{$\begin{array}{l}\text { Used the FOI } \\
\text { Act to obtain } \\
\text { information }\end{array}$} & $\begin{array}{l}\text { Civil } \\
\text { Society }\end{array}$ & Media & $\begin{array}{l}\text { Others- } \\
\text { demand }\end{array}$ & TOTAL \\
\hline No & $5(36 \%)$ & $14(78 \%)$ & $2(50 \%)$ & $21(58 \%)$ \\
Yes & $9(64 \%)$ & $3(17 \%)$ & $2(50 \%)$ & $14(39 \%)$ \\
No response & - & $1(5 \%)$ & - & $1(3 \%)$ \\
\hline TOTAL & $14(100 \%)$ & $18(100 \%)$ & $4(100 \%)$ & $36(100 \%)$ \\
\hline N=36 & & & &
\end{tabular}

\subsection{Research Question 3: Extent to Which Government MDAs have Supplied Information in Response to Requests Citing the FOIA}

Meanwhile, from the respondents from the government MDAs aware of the FOI Act, less than a third $(27 \%)$ indicated that they had been asked to provide information based on the FOI Act as shown in Table 4. Of the eight respondents that confirmed that they had to provide information as a result of the FOI Act, only one, a respondent from the government demand-side, said that the information was not provided. It appears that Government on the budget data supply-side are 
serious about making the FOI Act work. For instance, the Accountant General of the Federation (AGF) while being interviewed said that the AGF's Office had responded positively to requests invoking the FOI Act. He said that the process adopted is to send such requests to the Legal department, and the information requested is released based on the advice from that department.

Table 4: Government Respondents Who Have Faced an FOI Request

\begin{tabular}{lccc}
\hline Aware of the & \multicolumn{2}{c}{ Category } & TOTAL \\
\cline { 2 - 3 } FOI Act & Government & Government & \\
& demand-side & Supply-side & \\
\hline No & $6(86 \%)$ & $15(65 \%)$ & $21(70 \%)$ \\
Yes & $1(14 \%)$ & $7(31 \%)$ & $8(27 \%)$ \\
No response & - & $1(4 \%)$ & $1(3 \%)$ \\
\hline TOTAL & $7(100 \%)$ & $23(100 \%)$ & $30(100 \%)$ \\
\hline N=30 & & &
\end{tabular}

\subsection{Research Question 4: Extent to which FOIA is Promoting Access to Public Information}

Respondent opinion was sought on the extent to which the FOI Act will promote data access for citizens through in-depth interview of 15 major stakeholders across all the stakeholders groups sampled in this study. The insights from each stakeholder category are presented quoting the main points in their opinion.

Civil society respondents essentially noted that the law promotes wide access to data and information across the board although its implementation is somewhat slow and information is not readily given even when it is basic.

As one of the respondents put it:

Although in its infancy stage, the FOIA remains a very good tool for data access. At present, its invocation is very low, probably as a result of poor legal understanding and enforcement. To the extent consistent with the public interest, protection of the privacy of citizens and protect serving public officers, the law promotes wide access to data and information across board but implementation is somewhat slow and information is not readily given even when it is basic.

The general opinion of the civil society group as quoted above is supported by the majority of the respondents from the Government demand-side who also believe that the law is yet to be fully invoked and used to the maximum advantage possible. Nevertheless, they believed that if it is well used, the law has a lot of potential benefits that can improve transparency and promote good governance in Nigeria. It can increase access to public information and, therefore, can improve the participation of the citizens in governance.

To the media stakeholder category, FOIA is useful in its potentials to promote citizens' access to public information, but the potentials are reduced to nothing with the slow pace from the supplyside in supplying the information requested. Their opinion is that journalists are not encouraged to utilize or invoke the law because they are being denied by the supply-side when they make requests. To them, some of the inherent exceptions are also a discouragement to the invocation of 
the law, and which, according to them, make journalists hesitant to use or invoke the law. Thus, the invocation of the law has been made tedious by the inherent provisions of the Act. One of the respondents revealingly put the general opinion of the media stakeholders group this way:

FOI Act ordinarily promotes data access to citizens but the reverse is the case often because when the FOI Act is invoked government officials don't cooperate. I believe the FOI Act is very important for citizens and can really help in promoting access to data, if citizens will effectively use it.

Another respondent from the media added that:

The Act is potent enough to do this [increase citizens' access to public information] but it is not domesticated in state while the federal officers do not allow it to work. To a greater extent, the law makes it very difficult for public/civil servants to hide information. Hitherto, civil servants claimed they were barred by an Act not to disclose information, but with this law, they have no excuse any longer to hide any information. However, some of the provision of the FOIA seems to make the law ineffective. But definitely, it is capable of promoting access to information. And I learnt that some people especially lawyers have been accessing FOI.

Although many of the respondents among the media group mentioned various hindrances to the implementation of FOIA, several quotes identified the seemingly most significant hindrance, to be the refusal of States to domesticate the law and the uncooperative stance of government officials in providing requested information in a timely manner

Other demand-side respondents had similar opinion that the law has enormous potential for increasing the access of citizens to public information that can influence an open data culture in Nigeria. One of the respondents said, "on average I think the law can make access to information easy and guarantees that information could be sourced from anywhere when necessary", and added that, "it has been mixed experience. Even though we get responses, many are still grossly inadequate. We have used the FOI 17 times on getting actual expenditure of the budget and we are yet to get a favourable response". This highlights a major problem - that of information or data that is provided in response to the request, but the information is not useable for one reason or the other.

The government supply-side respondents, however, made some clarifications on the opinion, mainly from the media group, that the supply-side has been so uncooperative because they have not been responding adequately to requests. One of the respondents on the supply-side said that:

To a very large extent, we have been granting the requests made to us excluding personal information and documents that threaten the security of the nation. I agree the FOI act promotes data access to citizens to about $40 \%$ because even if a stakeholder is willing to give out a piece of information with respect to the FOI act, sometimes, the stakeholder is discouraged by the pressure they mount on him, giving him not enough time to deliver. However, the delay on the supply-side might be due to different reasons which may be official. 


\subsection{Research Question 5: Opinion of Stakeholders on How the FOIA Could Affect the Drive for Open Data in Nigeria}

Respondent opinions were sought on how the FOIA Act could impact on the drive for open data in Nigeria. The separate groups of stakeholders held very divergent opinions on this issue, but they seemed to agree on the potentials of the Act to institute and inculcate a strong open data culture in the Nigerian political system.

One of the respondents among the civil society group noted that the Act could potentially and positively impact on the open data culture in Nigeria if information is made available to those that request for them in digital format. As he put it:

If the information is made available in a timely manner and in an easily managed digital format, the Act is great and has great potential for improving our open data system in Nigeria. In a great way, the FOIA in Nigeria has indeed started driving the open data evangelism in that it is established in the law (asking for information). Nevertheless, it would be sustainable if government themselves will realize the benefit of making these data sets open. It will increase requests for information and documents. It will also help if a specific FOI desk officer in all the public institutions for ultimate compliance is trained for the job.. So, if the Act were properly implemented, it would have a huge impact because information would be widely available making open data truly open. It will assist the public to obtain information.

Respondents from the Government demand-side also concurred with this opinion which was encapsulated by one of them in this remarkable quote:

If properly publicised, it could bring about more demand for data and so trigger more supply. It will ensure that information is not concealed at any quarter, and it is made available to anyone in need, in real time. It would enable members of the public to know what they seek to know. This should increase trust for the government. The FOI Act will increase the need for accountability and by using open data there is an increase in public understanding. When the Act is in print for sale and run by newspapers, more people will be more aware of it and understand it better for proper utilization. Yes, the Act will strengthen the chance for open data. Once the Act is well understood, it will facilitate cooperation from all concerned to open data.

One of the responses from the Media group was also encapsulating of the general opinion of the respondents from this group. The response succinctly put it that the real essence of FOIA is to drive open data because open data is a means of making available public information to all and sundry that might need it to strengthen transparency and accountability or for any other objective. According to the respondent, there is, therefore, the need to understand the Act by all stakeholders to properly and adequately utilize it for positive impacts on the establishment or reinforcement of open data culture in Nigeria. Other demand-side respondents also mentioned the fact that proper implementation of the Act is key to driving open data in Nigeria because its implementation will facilitate easy access to public information, which is the cornerstone of the open data initiative.

From the government supply-side, respondents held the view that open data is the essential element of modern democracy, and it can only be driven if all people are given the right to access 
public information with which they can monitor and challenge government officials. According to one of them:

The FOI Act will impact the drive for good governance such that: there will be timely release of data. There will be applications and visualisation of government data, crowd sourced data on pot holes made open in visuals could inform the government of pot holes and government can respond to these. Government will avoid fund mismanagement, government will ensure adequate and even distribution of budget on roads, works, education, etc., across all states. Knowing data on the budget is released, government will ensure implementation.

In espousing the benefit of the FOI on open data culture and hence the subsequent caution placed on government to be more careful in their actions, one of the respondents from the supplyside noted that:

If the government knows that people have access to information on how they are governed they will be more careful. Corruption will be minimal. Because open data through FOIA gives the citizens access to any document. So the Act and open data it drives will lead to easier access to restricted documents and general awareness, transparency, effective and efficient Administration (Value for money). It will give the Nigerian Citizen the right to information. FOI will impact positively for good governance by letting populace know and have good information. If the government knows that people have access to information on how they are governed they will be more careful. It requires full exploitations by Nigerians. To make it functional and abiding on public officers, it must be honestly implemented and requests must be made for the purpose of public interests.

\subsection{Discussion of Findings}

Most stakeholders understand the concept of "open data". Similarly, almost all open data stakeholders indicated awareness of the FOI Act. This corroborated Abia's (2012) finding that many of the journalists he interviewed had great awareness and understanding of the relevance of the FOI laws and followed its cause keenly towards its effectiveness. However, a small proportion of the media/journalists has invoked the FOIA (17\%) compared to $64 \%$ from civil society. This also supports the finding by Omotayo (2015) that the people (journalists in particular) to whom the law gives access and for whom the law was enacted are not proactive in the usage of the law. It also buttresses Haynes (2009) submission that the adoption of FOI law in a country does not necessarily mean that the law is used and utilized effectively such that it could produce relevance in espousing democratic principles and tackling corruption in a country.

Meanwhile, the finding here is contradictory to what Banisar (2006) found about the use of FOIA by the journalists in Brazil. According to Banisar, media practitioners in the country have implemented the law, using it to monitor government activities, identify inconsistencies, and reveal corrupt public official. Similarly, this law has encouraged a lot of investigative journalism practices that have led to the public prosecution of corrupt officials and resignation of some ministers in the country (Martini, 2014). It is also different from what Haynes (2009) found about Mexican journalists, where Mexicans, mainly journalists, explored the freedom of information law so much that government officers complained of the enormous work of searching for information. 
While all respondents from the government supply-side admitted to providing the information requested based on the FOI Act, the study found that majority of the respondents from the government demand-side were reluctant to comment on the FOI leading to $64 \%$ of the 22, leaving the question on awareness of the FOI Act blank. This should raise a red flag as it suggests that the internal workings of the government have not fully embraced the principle of freedom of information. With such an attitude, it is not surprising that there were several allusions to uncooperative response to FOI requests by government officials.

Civil society respondents essentially noted that the law promotes wide access to data and information across the board although its implementation is somewhat slow, and information is not readily given even when it is basic. This agrees with what Omotayo (2015) found; that the poor usage of freedom of information laws in Nigeria is influenced by internal factors. The scholar noted that there is no proof that federal government institutions charged with the responsibility of ensuring the disclosures of information upon requests are complying with the law. This is also supported by the journalists sampled in this study. According to them, FOIA is good in its potential to promote citizens' access to public information, but this potential is reduced to nothing with the seeming hesitation of government MDAs in supplying the information requested. To them, some of the inherent exceptions are also a discouragement to the invocation of the law, and, according to them, make journalists hesitant to use or invoke the law. Thus, the invocation of the law has been made tedious by the inherent provisions in the Act. This is also in line with Ogbuokiri (2001) who affirmed that the excessive exemptions and clauses contained in the law stand as a significant challenge towards the effectiveness and proper implementation of the FOI law in Nigeria.

On the government demand-side, however, the belief is also that the law is yet to be fully internalised, particularly by the journalists, and it has not been used to significant advantage. To them, to a considerable extent, they have been granting the requests made to them, excluding personal information and documents that threaten the security of the nation. Nevertheless, they believe that if it is well used, the law has a lot of potential benefits that can improve transparency and good governance in Nigeria. So as this study also found out, some of the provision of the FOIA seems to make the law ineffective. More importantly, the format in which requested information is provided has a strong influence on if and when that information becomes open data. As Rose-Ackerman and Palifka (2016) point out, many countries must first put information systems in order. This will ensure that the available information can more easily be analysed faster.

One of the most significant hindrances to the effectiveness of FOIA identified, is the reluctance of States in Nigeria to domesticate the law. At the State level, it has been difficult to invoke the law to access information that can benefit the public. The reason for this is in Nigeria's federal system of government. While the Federal MDA's are compelled by the 2011 FOI Act to action, it seems MDAs in each of the 36 states of the Federation are only bound if the FOI legislation is passed in the state. The legality of this position has been contested in court with very opposing rulings. While a judge in Oyo state ruled in November 2014 that the FOI law covered the state, the Lagos 
state government has asked a court in Lagos to dismiss an FOI request that was made in December 2014 (Freedominfo.org, 2014).

To a considerable extent, stakeholders consensually agreed that the FOIA can improve open data culture in Nigeria. It can enforce disclosure of information otherwise restricted; it can give freer access to citizens to obtain information that are not classified because officials know the implication of not making such information available. So, they agreed that the Act could potentially and positively influence the open data system in Nigeria if information is made available to those who request them in digital format. This is in line with Banisar's (2006) findings that the use and adoption of the law enhances fundamental human rights, openness in government, equality, effective participation in governance, and the protection of citizens' rights.

Other demand-side respondents also concurred to the fact that proper implementation of the Act is crucial to driving open data in Nigeria because its implementation will facilitate easy access to public information, which is the cornerstone of open data initiative. However, some have asked whether the two, FOI and open data, are competing or complementary. In 2013, the UK Information Commissioner warned that open data is not a substitute for FOI because, through open data, the government provides what data it wants the public to see rather than to provide information based on the requests made (Curtis, 2013). Canares (2016) asserts that while FOI and open data differ in their approach, their aim is aligned, and that research shows that "FOI and open data efforts can actually complement one another".

\subsection{Conclusion and Recommendations}

The study targeted the sectors, positions, and persons with authority or influence to create change in the open data - FOI uptake. As stated earlier in the methodology section, obtaining consent from all the organisations such as the MDAs, media houses, and CSOs, was laborious and resourceconsuming. However, the effort paid off in the quality of interviews achieved and the subsequent insight as a result. Also, as informed consent was a necessary aspect of the research design, the necessary consent was sought to allow for the quotes by respondents that have been included in the paper. Although not all stakeholders have been interviewed, we believe that the conclusions drawn are still valid in the context of Nigeria.

The study confirmed that awareness is widespread about the existence of a Freedom of Information Act in Nigeria, but citizens are not taking sufficient advantage of this legal enabling policy. Journalists in particular to whom the law gives access and for whom the law was enacted are not proactive in the usage of the law. Thus, we find a poor usage of the FOIA in Nigeria. This is influenced by some factors such as non-compliance of the head of government and public institutions that are charged with supplying information on requests, hesitation by many government MDAs to supply the information requested, to supply inadequate data or information in response to requests, inherent exceptions in the law, and refusal of the States in Nigeria to domesticate the law. 
Our study clearly shows that there are elements that appear in both open data and freedom of information practice and results. One is the belief on the part of various stakeholder groups that both contribute to transparency and accountability. Another is the inherent pursuit of freedom of information as a driver of open data culture in the country. Furthermore, the degree of uptake appears to be at the same level in both cases. Essentially, the study has established a strong intersection between open data and the Freedom of Information Act and they are complementary rather than competing.

The FOIA can improve open data culture in Nigeria. It can enforce disclosure of information otherwise restricted; it can give free access to citizens to obtain information that is not classified because officials know the implications of not making such information available. The Act could potentially and positively affect the open data system in Nigeria if the information is made available to those that request for them in digital format. In essence, the Act will affect positively open data because open data is one of the means through which information is made accessible.

We recommend to the civil society in Nigeria to accelerate filings in the courts to obtain a legal stand on the 2011 FOI Act and the States of Nigeria. This is important because if there are still legal grounds for prevarication, some FOI requests in the states will go untreated. In terms of curbing corruption and promoting accountability, the sooner the states are also held accountable to disclose information the sooner corrupt practices at State level, which control about $40 \%$ of fiscal revenue, will begin to fall.

To the government, we recommend proper internalisation of the FOI Act and strengthening record keeping processes and information systems in preparation for FOI requests and open government data platforms. There is a need for proper implementation mechanisms that will facilitate easy access to public information and desk officers are vital in each MDA. Another important aspect of such implementation mechanisms is a strong enlightenment campaign to increase the understanding of the FOI Act in a way that stakeholders, both within and outside the government, will become determined to get the information or data that they need from relevant government MDAs; and thus the government MDAs will respond positively to such requests without fear of victimisation.

As future research, it is recommended to conduct further studies to investigate the extent of the use of FOI Act and impact of its use on the enhancement of open data culture in Nigeria. Such studies should involve a larger sample than what was adopted for the survey part of this study. Also, a specific case study and an analysis of successful and failed FOI requests by open data proponents in Nigeria would be of interest. Such research would show the existing process in the FOI request cycle, the format in which the information was provided, and how the information was used, if successful. And if not successful, an examination of the underlying factors would be fruitful.

\section{References}

Abia, K.M. (2012). An evaluative study of the freedom of information act and media practice in Nigeria. Retrieved via: www.academis.ng on 15/11/2016. 
Adeleke, F. (2011). Prospect and challenges of FOI bill in Nigeria. Retreived via: http://www.elombah.com on $18 / 11 / 2016$.

Afolayan, A. (2012). A critical analysis of freedom of information act in Nigeria. Retrieved via: https://odinakadotnet.wordpress.com on 15/11/2016.

Agande, B. (2011). FOI act and you! How the freedom of information act affects you. Retrieved via: www.vanguardngr.com on 14/11/2016.

Albu, O. B., \& Flyverbom, M. (2013). Categories and Dimensions of Organizational Transparency. In The 3rd Global Conference on Transparency Research.

Author (2014).

Banisar, D. (2006). Freedom of information around the world 2006, a global survey of access to government information laws. Retrieved via: www.freedominfo.org/.../global_... on 17/11/2016.

Canares, M. (2016). Open data and freedom of information: complements or competitors? Retrieved via: https://webfoundation.org/2016/09/open-data-and-freedom-of-information-complements-orcompetitors/ on 19/11/2017.

Coker, O. (2011). The emergence of Nigeria's freedom of information act 2011. Retrieved via:www.internationallaoffice.com/Newsletters/IT-internet/Nigeria/Kola-Awodein-Co/Theemergence-of-Nigeria-Freedom-of-information-Act-2011 on 15/11/2016.

Cordis, A.\& Warren,P. (2012). Sunshine as disinfectant: The effect of state freedom of information act laws on public corruption. Retrieved via: http:// papers.ssrn.com/sol3/papers.cfm?abstract_id=1922859 on 19/11/2016.

Costa, S. (2009). Do Freedom of Information Laws Decrease Corruption?. Retrieved via: http://www.unodc.org/unodc/crime_convention_corruption.html on 17/11/2016.

Curtis, S. (2013). Information Commissioner: 'Open Data is no substitute for freedom of information'. The Telegraph, 29 October 2013.2 Retrieved via: http:/ / www.telegraph.co.uk/technology/news/10412374/Information-Commissioner-Open-data-isno-substitute-for-freedom-of-information.html on 19/11/2017.

FOIA (2011). Freedom of Information Act (FOIA). Abuja: Federal Republic of Nigeria.

FOIA Advocates. (2016). Freedom of information act; frequently asked questions. Retrieved via: www.foiadvocates.com on 15/11/2016.

FOIC (2011). Freedom of Informatio Coalition (FOIC). Retrieved via: http://www.foiicoalition.org on $17 / 11 / 2016$.

Freedominfor.org. (2014). Application of Nigerian FOI Law to States Contested. Retrieved via: http://www.freedominfo.org/2014/02/application-nigerian-foi-law-statescontested/ on 19/11/2017.

Hayes, J. (2009). A shock to the system: Journalism, government and the freedom of information act 2000. Working paper. Reuters Institute for the study of Journalism, University of Oxford. 
IIEA (2011) The UK Open Data Initiative - Lessons Learnt and Challenges for the Future, Institute of International and European Affairs. Retrieved September 5, 2012 from http://www.iiea.com/events/the-uk-open-data-initiative---lessons-learnt-and-challenges-forthefuture?gclid=CKCj79Wwh7ICFQjf4Aod2GEApA

Joshi, A. (2010). Review of impact and effectiveness of transparency and accountability initiatives, Annex 1: Service Delivery. Transparency and Accountability Initiative, 1-17.

Martini, M. (2014). Right to information laws: Impact and implementation. Retrieved via: http://www.trans parency.or on 20/11/2016.

Mendel, T. (2008). Freedom of information: a comparative legal survey. Second edition. UNESCO. Retrieved via: http:// portal.unesco.org/ci/en/files/26159/12054862803freedom_informatio n_en.pdf/freedom_information_en.pdf on 15/11/2016.

Mendel, T. (2005). Freedom of Information as an Internationally Protected Human Right. Retrieved via: http://www.article19.org on 15/11/2016.

Neuman, L. (2005). A key to democracy: Access to information critical for citizens, government. Retrieved via: www.cartercenter.org on 15/11/2016.

Offiong, M. (2013). Impact of freedom of information act on journalism practice: A study of journalism practice in Uyo community from January- June 2013.

Ogbondah, C. W. (2003). State Press Relationship in Nigeria (1993-1998). Ibadan: Spectral Books Limited

Ogbuokiri, K. (2001). Nigeria: The limit of information act in freedom of information act 2011 and the fight against corruption and corporate fraud in governance. Retrieved via: http://www.allafrica.com on $19 / 11 / 2016$

Omotayo, F.O. (2015). The Nigeria freedom of information law: Progress, implementation, challenges and prospects. Journal of Library Philosophy and Practice, p 1-17.

Rose-Ackerman, S. \& Palifka, B.J. (2016). Corruption and Government: Causes, Consequences, and Reform. Cambridge University Press. 